\title{
Tissue plasminogen activator, plasminogen activator inhibitors, and activator-inhibitor complex in liver disease
}

\author{
K Leiper, A Croll, N A Booth, N R Moore, T Sinclair, B Bennett
}

\begin{abstract}
Aims-To identify the relative contribution of plasminogen activators, particularly tissue plasminogen activator (t-PA) and specific plasminogen activator inhibitors (PAI-1, PAI-2), to the fibrinolytic changes associated with various types of liver disease or severe chemical and physical damage to the liver.

Methods-Platelet rich (PRP) and platelet poor plasma (PFP) from patients with alcoholic cirrhosis, primary biliary cirrhosis, hepatic malignancy, or paracetamol overdose, or who were undergoing partial hepatectomy or liver transplantation, were assayed for t-PA, PAI-1, t-PAPAI-1 complex and PAI-2 antigen values using specific enzyme linked immunosorbent assays (ELISAs) developed in this laboratory.

Results-Appreciable increases in the plasma concentration of t-PA, PAI-1, and t-PA-PAI-1 were seen in patients with alcoholic cirrhosis, primary biliary cirrhosis, and hepatic malignancy. Liver damage due to paracetamol overdose and partial hepatectomy both resulted in a striking increase in plasma PAI-1 concentration, although concentrations of $t-$ PA and t-PA-PAI-1 complex were less affected. Concentrations of t-PA, PAI-1, and t-PA-PAI-1 complex returned to near normal values after successful liver transplantation in a patient with chronic active hepatitis. PAI-2 was also detected in several patients with chronic liver disorders.
\end{abstract}

Conclusions-Haemorrhage due to fibrinolytic bleeding is commonly associated with liver disease. The patients studied here all had appreciable increases in circulating t-PA antigen concentrations. This was associated with increased concentrations of PAI-1 antigen and t-PAPAI-1 complex and the balance between activator and inhibitor did not result in systemic plasmin generation. Reduced PAI-1 activity in cirrhosis or a critical difference in the ratio of t-PA to PAI-1 concentrations may explain the enhanced plasminogen activator activity previously noted in cirrhosis but not metastatic disease. Reduced hepatic clearance of $t-P A$ and t-PA-PAI-1 complex due to impaired liver function may account for increased concentrations of free and complexed t-PA.

(f Clin Pathol 1994;47:214-217)
Liver disease is associated with several abnormalities of the fibrinolytic system. Early studies of "overall fibrinolytic activity" showed that it was increased in hepatic cirrhosis. ${ }^{1-4}$ This finding might be explained by increased plasmin activity secondary to the reduced concentrations of the principal plasmin inhibitor $\left(a_{2}\right.$ antiplasmin) observed in cirrhosis ${ }^{5-8}$; however, major generation of complexes of plasmin and antiplasmin was not observed in the plasma of patients with cirrhosis, despite the presence of large amounts of free plasminogen activator (PA) and low $a_{2}$ antiplasmin concentrations. ${ }^{9}$ Enhanced overall fibrinolytic activity in plasma probably reflects principally increased circulation of plasminogen activator in cirrhosis and evidence shows raised t-PA and u-PA activity $^{9}$ and t-PA antigen ${ }^{10}$ in such patients. Reduced hepatic clearance of PA may contribute to raised plasma activities of PA in patients with cirrhosis. ${ }^{3}$ Alternatively, reduced concentrations of inhibitors of PA might account for raised PA activity. However, concentrations of such inhibitors were normal or increased in previous studies on hepatic cirrhosis, ${ }^{10}$ a fact which might account for the failure to generate plasmin in the circulation indicated above.

In contrast with hepatic cirrhosis, patients with hepatic malignancy, primary or secondary, have usually depressed overall fibrinolytic activity. ${ }^{3411}$ However, raised concentrations of t-PA and u-PA antigen have recently been reported. ${ }^{10}$ If these were associated with high PAI-1 values this might explain the finding of reduced fibrinolytic activity. Few data are available on forms of liver disease other than alcoholic cirrhosis and malignancy and no systematic search for both the principal inhibitors of PA, PAI-1, and PAI-2 has been made in liver disease. We studied $t-$ PA, PAI-1, t-PA-PAI-1 complex, and PAI-2 in several forms of liver disease to clarify the behaviour of the fibrinolytic system when hepatic function is abnormal.

\section{Methods}

Twenty five patients with liver disorders were studied. Twelve were identified as having alcoholic cirrhosis and five as having primary biliary cirrhosis on the basis of appropriate clinical history, biochemical results, autoantibody values, and results of liver biopsy. Five patients had extensive hepatic metastatic disease identified on liver scanning, all having clearly defined primary sites and clinical and biochemical evidence of severe liver 
dysfunction. Two patients were studied on admission to hospital immediately after severe paracetamol overdose as a model for acute chemical hepatic damage. A further patient was studied sequentially over the period of partial hepatectomy for a very extensive benign adenoma; this patient serves as a model for acute physical hepatic injury. One patient with end stage liver failure due to chronic active hepatitis was studied several weeks before and several weeks after liver transplantation.

Blood samples were taken into $0 \cdot 1$ volume of $0.13 \mathrm{M}$ sodium citrate between 8.30 and $9 \cdot 30$ am with minimal stasis and trauma. Plasma essentially free of platelets (PFP) was prepared by centrifugation at $4^{\circ} \mathrm{C}$ for $30 \mathrm{~min}$ utes at $1850 \times g$. Platelet rich plasma $(P R P)$ was obtained by centrifugation at $170 \times g$ for 10 minutes at room temperature. The platelets were then lysed by use of an MSE ultrasonic disintegrator at five second bursts at full power. Platelets were counted using a Coulter Thrombocounter C for PFP and PRP both before and after sonication. Thereafter all samples were stored in small aliquots at $-70^{\circ}$, thawing of samples being kept to a minimum.

Liver function tests were performed by standard techniques. PAI-1, t-PA, t-PA-PAI1 complex, and PAI-2 were measured by specific enzyme linked immunosorbent assays (ELISAs) as described previously. ${ }^{12-15}$

The Wilcoxon signed rank test for unpaired data was used to compare results; $p$ values are quoted for comparisons between patients and normal controls.

\section{Results}

Table 1 summarises platelet counts and the results of clinical biochemistry for the groups of patients with different forms of liver disease. In the three main groups of liver disorder studied-namely alcoholic cirrhosis, primary biliary cirrhosis, and hepatic malignancy-plasma concentrations of t-PA, PAI-1, and t-PA-PAI-1 complex antigens were appreciably raised (table 2). t-PA and t-PAPAI-1 complex antigen concentrations were highest in alcoholic cirrhosis, while PAI-1 antigen concentrations was highest in hepatic metastases. The concentration of PAI- 1 in the platelet pool in each group was reduced; however, this reflected reduced platelet counts and the mean platelet content of PAI-1 did not differ from that of normal subjects (data not shown).

The two patients with severe chemical damage to the liver caused by paracetamol overdose showed strikingly raised concentrations of PAI- 1 but only a modest increase in tPA and t-PA-PAI-1 antigen (table 2).

The changes in PAI-1, t-PA, and t-PAPAI-1 complex antigen induced by acute mechanical trauma to the liver (partial hepatectomy) were also studied (figure). A dramatic rise and rapid fall in PAI-1 antigen values was observed over 48 hours. Concentrations of tPA and t-PA-PAI-1 complex rose also, but these rises followed rather than coincided with the PAI-1 response.

In the patient with end stage liver failure, concentrations of t-PA, PAI-1, and t-PA-PAI1 complex before transplantation were all

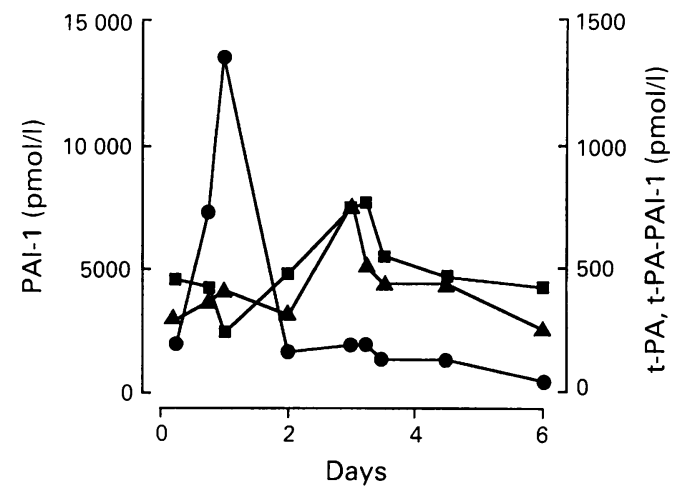

Changes in plasma concentrations of $t-P A(\Delta-\Delta), P A I-1$ $(\bullet-\bullet)$, and $t-P A-P A I-1$ complex ( $\square-\square)$ after partial hepatectomy.

Table 1 Mean values of biochemical variables of liver function in patients with different forms of liver disease

\begin{tabular}{|c|c|c|c|c|c|c|}
\hline & $\begin{array}{l}\text { Albumin } \\
(\mathrm{g} / \mathrm{l})\end{array}$ & $\begin{array}{l}\text { Bilirubin } \\
(\mu \text { molll })\end{array}$ & $\begin{array}{l}\text { Alkaline } \\
\text { phosphatase } \\
\text { (UIl) }\end{array}$ & $\begin{array}{l}\text { Amino } \\
\text { aspartase } \\
\text { transaminase } \\
\text { (U/l) }\end{array}$ & $\begin{array}{l}\gamma \text { Glutamyl } \\
\text { transferase } \\
\text { (UIl) }\end{array}$ & $\begin{array}{l}\text { Platelet } \\
\text { count } \\
\left(10^{9} / \mathrm{l}\right)\end{array}$ \\
\hline $\begin{array}{l}\text { Alcoholic cirrhosis }(n=12) \\
\text { Primary biliary cirrhosis }(n=5) \\
\text { Hepatic metastases }(n=5) \\
\text { Paracetamol overdosage }(n=2) \\
\text { Normal values }\end{array}$ & $\begin{array}{l}32 \\
37 \\
39 \\
40 \\
37-49\end{array}$ & $\begin{array}{r}105 \\
62 \\
94 \\
15 \\
<22\end{array}$ & $\begin{array}{l}178 \\
423 \\
894 \\
30 \\
<105\end{array}$ & $\begin{array}{r}83 \\
100 \\
158 \\
38 \\
<31\end{array}$ & $\begin{array}{r}181 \\
690 \\
380 \\
10 \\
<35\end{array}$ & $\begin{array}{l}200 \\
122 \\
188 \\
200 \\
150-400\end{array}$ \\
\hline
\end{tabular}

Table 2 Mean (SD) concentrations of $t-P A, P A I-1, P A I-2$, and $t-P A-P A I-1$ complex in platelet free plasma of patients with different forms of liver disease

\begin{tabular}{|c|c|c|c|c|c|}
\hline & $t-P A(n g / m l)$ & $P A I-1(\mathrm{ng} / \mathrm{ml})$ & $\begin{array}{l}t-P A-P A I-1 \text { complex } \\
(p m o l / l)\end{array}$ & $P A I-2(n g / m l)$ & $\begin{array}{l}a_{2} \text { Antiplasmin } \\
(\% \text { normal })\end{array}$ \\
\hline $\begin{array}{l}\text { Alcoholic cirrhosis } \\
\text { Primary biliary cirrhosis } \\
\text { Hepatic metastases } \\
\text { Paracetamol overdose } \\
\text { Normal values }\end{array}$ & $\begin{array}{l}47 \cdot 1(20 \cdot 8)^{\star \star} \\
31 \cdot 6(9 \cdot 0)^{\star \star} \\
32 \cdot 3(10 \cdot 9)^{\star \star} \\
20 \cdot 36^{\star \star} \\
5 \cdot 1(2 \cdot 0)\end{array}$ & $\begin{array}{l}55 \cdot 9(35 \cdot 5)^{\star \star} \\
57 \cdot 6(31 \cdot 3)^{\star \star} \\
72 \cdot 7(65 \cdot 7)^{\star} \\
200 \cdot 8^{\star \star} \\
21 \cdot 0(7 \cdot 2)\end{array}$ & $\begin{array}{l}804 \cdot 7(534 \cdot 6)^{\star \star} \\
413 \cdot 0(134 \cdot 2)^{\star \star} \\
372 \cdot 8(279 \cdot 6)^{\star \star} \\
250 \cdot 88^{\star} \\
60 \cdot 3(45 \cdot 5)\end{array}$ & $\begin{array}{l}8 \cdot 2(6 \cdot 8) \\
8 \cdot 4(0 \cdot 2) \\
9 \cdot 5(0 \cdot 2) \\
16 \cdot 5 \\
0\end{array}$ & $\begin{array}{l}69 \cdot 0(18 \cdot 7)^{\star \star} \\
72 \cdot 2(24 \cdot 4)^{\star \star} \\
91 \cdot 0(21 \cdot 0)^{\star} \\
\mathrm{NA} \\
112 \cdot 3(11 \cdot 2)\end{array}$ \\
\hline
\end{tabular}

NA $=$ not assayed

${ }^{\star} \mathrm{p}<0.01,{ }^{\star \star} \mathrm{p}<0.001$ 
Table 3 Concentrations of $t-P A, P A I-1$, and $t-P A-P A I-$ 1 complex in platelet free plasma before and after liver transplantation

\begin{tabular}{llll}
\hline & t-PA $(\mathrm{ng} / \mathrm{ml})$ & $P A I-1(\mathrm{ng} / \mathrm{ml})$ & $\begin{array}{l}t-P A-P A I-1 \\
\text { complex } \\
(\text { pmoll })\end{array}$ \\
\hline Before & $81 \cdot 2$ & $97 \cdot 7$ & $659 \cdot 3$ \\
After & 16.9 & 12.9 & $31 \cdot 3$ \\
\hline
\end{tabular}

strikingly raised; all returned to near normal after successful transplantation (table 3 ).

Ten of the 12 patients with alcoholic cirrhosis, two of the five with primary biliary cirrhosis, two of the four with hepatic malignancies and one of the two with paracetamol overdose had detectable plasma concentrations of PAI-2 (table 2).

Reduced circulating concentrations of $a_{2}$ antiplasmin were found in patients with alcoholic cirrhosis and primary biliary cirrhosis, with a less pronounced reduction in patients with hepatic metastases (table 2).

\section{Discussion}

These observations extend the findings of previous studies on proteolytic disorders in liver disease. Earlier studies have shown enhanced overall fibrinolytic activity in hepatic cirrhosis with no increase, or more commonly, a decrease in overall fibrinolytic activity in patients with hepatic metastases. These early studies used techniques such as the euglobulin lysis time reflecting primarily plasminogen activator concentration, and $\mathrm{t}$ PA antigen has been shown to be raised in cirrhosis. ${ }^{16}{ }^{17}$ Our earlier studies have shown that despite raised concentrations of PA and reduced concentration of $\alpha_{2}$ antiplasmin there was no evidence of significant generation of plasmin- $a_{2}$ antiplasmin complexes in patients with cirrhosis. ${ }^{89}$ This suggested that in cirrhosis there was sufficient inhibitor of PA present in plasma to prevent large scale generation of plasmin by the increased amounts of PA present. This study confirms this suggestion, as there is clearly a considerably increased concentration of PAI-1 in the plasma of cirrhotic patients, with generation of large quantities of t-PA-PAI-1 complex.

In the three major liver diseases studiedalcoholic cirrhosis, primary biliary cirrhosis, and metastatic liver disease-concentrations of t-PA, PAI-1 antigen, and t-PA-PAI-1 complexes were all considerably raised. Despite the raised concentration of PAI-1 antigen noted here, we observed reduced PA-I activity in hepatic cirrhosis ${ }^{48}$ and others have reported similar findings ${ }^{17}$; this may reflect large scale generation of t-PA-PA-I complex in cirrhosis and explain why significant t-PA activity remains, accounting for enhanced overall fibrinolytic activity. The differences in overall fibrinolytic activity between patients with cirrhosis and those with metastatic liver disease may depend on a critical balance between t-PA and PAI-1. Concentrations of $t-$ PA and PAI-1 were raised in all patient groups, but clearly the ratio of t-PA to PAI-1 antigen concentrations was higher in cirrhosis than in metastatic disease (table 2).

The highest concentrations of PAI-1 antigen were noted in patients with chemical (paracetamol) or physical (partial hepatic resection) injury to the liver. Paracetamol overdose represents a particularly acute form of liver damage and PAI-1 concentrations clearly were raised early, before large changes in standard biochemical variables of liver damage were detected; in this it is similar to the well known prolongation of the prothrombin time after overdose. Similar very early release of PAI-1 antigen occurred during partial hepatectomy in the one patient studied and this occurred before any change in concentration of $\mathrm{t}-\mathrm{PA}$ or t-PA-PAI-1 complex. These observations suggest that in liver disease the source of raised plasma concentrations of PAI-1 is the liver itself, PAI-1 being released from damaged liver cells at least in some situations. The source of raised concentrations of t-PA is less clear. The liver is not rich in t-PA but is responsible for clearance of $t-P A$ from the circulation both in its free and complexed forms. ${ }^{19-21}$ In liver disease it seems probable that raised concentrations of t-PA and t-PA-PAI-1 complexes result in part at least from reduced clearance mechanisms of both types. The restoration to virtual normality of t-PA, PAI-1, and tPA-PAI-1 complexes after liver transplantation strikingly emphasises the central role of the liver in securing homoeostasis in the fibrinolytic system.

PAI-2 is usually detected in pregnancy and has not been reported before in liver disease. This inhibitor is, however, synthesised by several cell lines in culture, including monocytes, macrophages, and certain tumour cells. In this study small but significant quantities of PAI-2 were detected by ELISA and by the independent technique of non-denaturing gel electrophoresis with zymography rendered specific by antibody quenching. ${ }^{22}$ The presence of PAI-2 may represent a response to the u-PA we have shown in the plasma in some forms of liver disease ${ }^{9}$ and which is often present in malignant cells. ${ }^{23}$ Alternatively, depressed hepatic function may reduce clearance mechanisms for PAI-2, which are as yet undefined, and may result in small quantities of PAI-2 produced by monocytes, etc, accumulating in the plasma.

In summary, this study shows that patients with major hepatic disease tend to have high concentrations of t-PA, PAI-1, and t-PA-PAI1 complex as detected by immunoassay, regardless of the type of liver disease. High concentrations of PAI-1 and perhaps PAI-2 may be an important factor in preventing generation of plasmin in these patients but do not account for the difference in overall fibrinolytic activity between patients with different forms of liver disease. Altered functional activity of the inhibitors or critical alterations of the ratio of t-PA to PA-1 concentration may be factors in the differences observed in PA activity. The raised concentrations of PAI1 may reflect in some cases release of PAI-1 from damaged liver cells, but increased PAI-1 
synthesis within or outwith the liver as a result of the metabolic disruption occurring in liver disease may occur. Raised t-PA concentrations may reflect, in part, reduced clearance by the damaged liver.

1 Ratnoff OD. Studies on a proteolytic enzyme in human plasma IV. The rate of lysis of plasma clots in normal
and diseased individuals with particular reference to and diseased individuals with particular reference to hepatic

2 Purcell G, Phillips LL. Fibrinolytic activity in cirrhosis of the liver. Surg Gynecol Obstet 1963;117:139-44.

3 Fletcher AP, Biederman O, Moore D, Alkjaersig N, Sherry S. Abnormal plasminogen-plasmin system activity (fibrinolysis) in patients with hepatic cirrhosis: its cure and consequences. F Clin Invest 1964;43:681-95.

4 Ogston D, Bennett B, Ogston CM. The fibrinolytic enzyme system in hepatic cirrhosis and malignant metastases. $f$ Clin Pathol 1971;24:822-6.

5 Saito H. Reduced histidine rich glycoprotein levels in plasma of patients with advanced liver cirrhosis. $A m \mathcal{F}$ Med 1982;73:179-82.

6 Saito H. $a^{2}$-Antiplasmin and its deficiency states. $f \mathrm{Lab}$ Clin Med 1988;112:671-8.

7 Hersch SL, Kunelis T, Frances RB. The pathogenesis of accelerated fibrinolysis in liver cirrhosis: a critical role for tissue plasminogen activator inhibitor. Blood 1987;69: 1315-9.

8 Sinclair TS, Booth NA, Penman SM, Brunt PW, Mowat NAG, Bennett B. Protease inhibitors in liver disease. Scand $\mathcal{F}$ Gastroenterol 1988;23:620-4.

9 Booth NA, Anderson JA, Bennett B. Plasminogen activators in alcoholic cirrhosis: demonstration of increased tors in alcoholic cirrhosis: demonstration of increased tissue type and
$1984 ; 37: 772-7$.

10 Tran-Thang C, Fasel-Felley J, Pralong G, Hofsetter JR, Bachmann F, Kruithof EKO. Plasminogen activators and plasminogen activator inhibitors in liver deficiencies caused by chronic alcoholism or infectious hepatitis. Thromb Haemostas 1989;62:651-3.

11 Kwaan HC, Lo R, McFadzean AJS. Antifibrinolytic activity in primary carcinoma of the liver. Clin Sci 1959;18: 251-61.
12 Booth NA, Simpson AJ, Croll A, Bennett B, MacGregor IR. Plasminogen activator inhibitor (PAI-1) in plasma and platelets. Br F Haematol 1988;70:327-33.

13 MacGregor IR, MacDonald S, Dawes J, Micklem LR, James K. A monoclonal antibody enzyme-linked immunosorbent assay (ELISA) directed towards a fibrin binding region of tissue-type plasminogen activator. Fibrinolysis 1987;1:247-52

14 Booth NA, Croll A, Bennett B. The activity of plasminogen activator inhibitor-1 (PAI-1) of human platelet. Fibrinolysis 1990;4(suppl 2):138-40.

15 Reith AR, Booth NA, Moore NR Cruickshank DJ, Bennett B. Plasminogen activator inhibitors (PAI-1 and PAI-2) in normal pregnancies, pre-eclampsia and hydatiform mole. Br F Obstet Gynaecol 1993;100:370-4

16 Leebeek FWG, Kluft C, Knot EAR, DeMaat MPM, Wilson JHP. A shift in balance between profibrinolytic and antifibrinolytic factors causes enhanced fibrinolysis in cirrhosis. Gastroenterology 1991;101:1382-90.

17 Huber K, Kirchheimer JC, Korninger C, Binder BR. Hepatic synthesis and clearance of components of the fibrinolytic system in healthy volunteers and in patients with different stages of liver cirrhosis. Thromb Res with different stage

18 Simpson AJ, Booth NA, Moore N, Bennett B. The platelet and plasma pools of plasminogen activator inhibitor (PAI-1) vary independently in disease. Br 7 Haematol 1990; 75:543-8.

19 Emeis JJ, van den Hoogen CM, Jense DE. Hepatic clearance of tissue-type plasminogen activator in rats. Thromb Haemostas 1985;54:661-4.

20 Wing LR, Hawksworth GM, Bennett B, Booth NA. Clearance of t-PA, PAI-1 and t-PA-PAI-1 complex in an isolated perfused rat liver system $f$ Lab Clin Med 1991;117:109-14.

21 Wing LR, Bennett B, Booth NA. The receptor for tissue plasminogen activator ( $t-P A$ ) in complex with its plasminogen activator (t-PA) in complex with its 278:95-7.

22 Reith A, Bennett B, Booth NA. Plasminogen activator inhibitor (PAI-2) in pregnancy plasma and ovarian cysts, studied by zymography after non-denaturing gel electrophoresis. Fibrinolysis 1989;3:159-63.

23 Benett B, Booth NA, Croll A, Dawson AA. The bleeding disorder in acute promyelocytic leukaemia: fibrinolysis due to u-PA rather than defibrination. Br $\mathcal{f}$ Haematol 1989;71:511-7. 